axis, no water is being frozen or melted with change in temperature. When the curve is vertical with respect to the temperature axis, pure water is being frozen or melted. When the curve is inclined to the temperature axis, ice is being separated from or melted into a solution, as in the concentration or dilution of a sugar solution. This latter effect may also be brought about by capillary forces or by colloidal substances the avidity of which for water varies with their concentration.

Fig. 3 shows the results obtained upon freezing fresh green peas using time as a variable instead of temperature. $19 \mathrm{gm}$. of green peas at room temperature were placed in the condenser and immersed in a thermostat held at $-16^{\circ} \mathrm{C}$. At the time of immersion and at intervals thereafter capacitance measurements were made. The time required for complete freezing is the time elapsed before the capacitance reaches a constant value. The curves shown are for mature and immature peas taken from the same lot. Since the condenser containing the peas was surrounded by an air jacket, it is possible that the rate of heat transfer was the limiting factor in the earlier part of the freezing time. The method offers the opportunity of determining when such substances are completely frozen throughout. It should be noted that the peas with the higher moisture content showed a greater capacitance change upon freezing. Possibly with improved technique, quantitative interpretation of the relation between capacitance change and the amount of ice formed may be made.

This method is being presented here in the hope that it may prove useful in fields outside those with which we are concerned. The data presented in this paper were obtained with the first apparatus built and are to be regarded only as representative of the type of results obtainable. The functions of the laboratory do not permit the following up of this problem from any except the soil point of view. It seems very probable that the method would be useful in studying the winter hardiness of plants, the freezing injury to fruits and vegetables, and storage temperature for meats. It may also be useful in preparation of frozen-pack foods.

Lyle T. Alexander. Thomas M. Shaw.

U.S. Department of Agriculture,

Bureau of Chemistry and Soils,

Washington.

April 13

1 Alexander, L. T., Shaw, T. M., and Muckenhirn, R. J., Proc. Soil Sci. Soc. America, 1, 1937 (presented before the meeting of the American Sci. Soc. America, 1, 1937 (presented
Soeiety of Agronomy, Nov. 1936).

\section{Radioactive Isotopes of Copper}

IN view of the fact that copper has only two stable isotopes ${ }_{29}^{63} \mathrm{Cu}$ and ${ }_{29}^{65} \mathrm{Cu}$, it is difficult to account for the large number of different half-life periods reported for radioactive copper isotopes. Of the two short periods of $6 \mathrm{~min}$. and $10.5 \mathrm{~min}$., the latter has been satisfactorily attributed to ${ }_{29}^{62} \mathrm{Cu}^{1,3,4}$. Periods of $6 \mathrm{~h}$. and $10 \mathrm{~h}$. have been obtained by neutron bombardment $t^{1,5}$ and a $12 \cdot 8 \mathrm{~h}$. period given by deuteron bom. bardment ${ }^{2,2}$. Since this latter product emits both positrons and electrons, there is good evidence for labelling it ${ }_{92}^{64} \mathrm{Cu}$. A radioactive copper has been chemically separated from zinc bombarded by fast neutrons, of half-life variously reported at $6 \mathrm{~h}$. and 10h. 15,8. Madsen has directed attention to the confusion over these periods and gives the half-life period of the copper obtained from zinc as $17 \mathrm{~h} .{ }^{7}$.

Leo Szilard, of the Clarendon Laboratory, Oxford, informed us that the decay curve of the copper bombarded by fast neutrons from radon-beryllium contained a period of a few hours which was absent when slow neutrons were used, or if the radioactive copper was obtained from zinc by fast neutron bombardment. It was arranged with him that further investigations and chemical separation should be made in this laboratory.

We irradiated $2 \mathrm{gm}$. mols of pure cupric oxide with fast neutrons from a 200 mc. radium-beryllium source. After irradiation, we dissolved the oxide, added $500 \mathrm{mgm}$. of nickel salt and precipitated the copper as cuprous iodide. The separated nickel after purification and conversion to nickel sulphide,

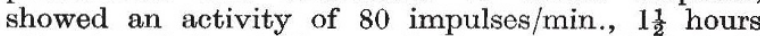
after irradiation had ceased, decaying with a halflife of $160 \pm 10 \mathrm{~min}$. We found the same half-life period in nickel irradiated by slow neutrons, in agreement with Rotblat, Naidu and $\mathrm{Heyn}^{2}$. It must be due to a radioactive isotope ${ }_{28}^{63} \mathrm{Ni}$ or ${ }_{28}^{65} \mathrm{Ni}$, and may be produced either from ${ }_{29}^{63} \mathrm{Cu}$ or ${ }_{29}^{65} \mathrm{Cu}$ by capture of a neutron and expulsion of a proton.

We found that copper irradiated with slow neutrons in the absence of fast neutrons showed an activity of half-life $13 \pm 0 \cdot 5 \mathrm{~h}$. and that the same half-life period was obtained by separating radioactive copper from zine bombarded by fast neutrons. In these experi. ments the initial activities were about 300 impulses/ min. with a background of 20 impulses/min.

This radioactive copper may well be identical with that produced by bombarding copper by deuterons and is accordingly likely to be ${ }_{29}^{64} \mathrm{Cu}$. The $6 \mathrm{~min}$. period of copper obtained by slow neutron capture would then be due to ${ }_{29}^{66} \mathrm{Cu}$.

No indication of a $6 \mathrm{~h} ., 10 \mathrm{~h}$. or $17 \mathrm{~h}$. period was obtained in our experiments.

Thanks are due to the Department of Scientific and Industrial Research for a grant and to Imperial Chemical Industries, Ltd., for the purchase of apparatus.
Department of Chemistry,
University, Manchester.
JAMES L. TUCK.
${ }^{1}$ Amaldi, E., Fermi, E., and others, Proc. Roy. Soc., A, 146, 483 (1934); A, 149, 522 (1935).
${ }^{2}$ Lawrence, Ernest O., and others, Phys. Rev., 46, 325 (1934); 48, 493 (1935).
${ }^{3}$ Heyn, A. F., Physica, 4, 160 (1937).
${ }^{4}$ Bothe, W., and Gentner, W., Naturwiss., 25, 30 (1937).
${ }^{5}$ Bjerge, T., and Westcott, C. H., NATURE, 134, 286 (1934).
${ }^{6}$ Van Voorhis, S. N., Phys, Rev., 49, 876 (1936); 50, 895 (1936).
' Madsen, C. B., Natrure, 138, 722 (1936).
${ }^{8}$ Livingood, J. J., Phys. Rev., 50, 425 (1937).
- Rotblat, J., NATURe, 136, 515 (1935). Naidu, R., NAtUre, 137, 578 (1936).

Erwin A. Oeser.

\section{Artificial Radioactivity produced by Fast Neutrons and their Inelastic Collisions}

Several investigators have reported that fast neutrons give rise to a transformation of an irradiated element in which the newly formed nucleus results from the original nucleus through the loss of a neutron ${ }^{1,2}$.

I have made some experiments on the activation of copper, zinc and silver by fast neutrons. As the efficiency in these cases is small, I used the following arrangement : A foil of the metal under investigation, 